\title{
Pterjiyum Cerrahisinde Fibrin Doku Yapıştırıcısı ve Vikril Sütür Tekniği
}

\section{Fibrin Tissue Adhesive and Vicryl Suture Technique in Pterygium Surgery}

Meydan Turan ${ }^{1}$,

${ }^{1}$ Balıkesir Atatürk Şehir Hastanesi, Göz Kliniği, Balıkesir, Türkiye

Gelis Tarihi/Received: 14 Mart 2020 Kabul Tarihi/Accepted: 19 Mayıs 2020

Yazışma Adresi: Meydan Turan, Balıkesir Atatürk Şehir Hastanesi, Göz Kliniği, Balıkesir, Türkiye

e-mail: meydanturan@gmail.com

ORCID

Meydan Turan

https://orcid.org/0000-0001-6593-9025

\begin{abstract}
Öz
Amaç: Kliniğimizde otogreftli pterjiyum cerrahisinde uyguladığımız fibrin doku yapıştırıcı ve vikril sütür tekniğininin karşılaştırılması amaçlandı.

Hastalar ve Yöntem: Haziran 2016 ve Ağustos 2019 tarihleri arasında ameliyatı yapılan hastaların dosyaları retrospektif olarak gözden geçirildi. Çalışmaya vikril sütür ile otogreftli pterjiyum cerrahisi yapılan 72 hasta (Grup 1), (primer pterjiyumlar Grup 1a, Nüks pterjiyumlar Grup 1b), fibrin doku yapıştırıcısı kullanılarak otogreftli pterjiyum cerrahisi yapılan 58 hasta (Grup 2), (primer pterjiyumlar Grup 2a, Nüks pterjiyumlar Grup 2b) dahil edildi. Her iki grupta cerrahi işlem süreleri ve komplikasyonlar not edildi. SPSS, 20.0 versiyon istatistik analiz programı kullanıldı. Veriler bağımsız örneklem $t$ testi kullanılarak değerlendirildi.

Bulgular: Gruplara dahil edilen hastaların yaşları Grup 1'de 37 ile 65 yıl arasında olup, ortalama yaş $47.04 \pm 5.70$ yıl iken, Grup 2'de 38 ile 57 yıl arasında olup ortalama yaş $47.10 \pm 4.88$ yıl idi. Gruplar arasında hastaların yaşı değerlendirildiğinde anlamlı fark görülmedi $(p=0.95)$. Ameliyatın ortalama süresi grup la, $1 \mathrm{~b}, 2 \mathrm{a}$ ve $2 \mathrm{~b}$ 'de sırasıyla $24.91 \pm 3.08 \mathrm{dk}, 25.60 \pm 2.20 \mathrm{dk}, 17.62 \pm 2.57 \mathrm{dk}$ ve $18.84 \pm 2.83 \mathrm{dk}$ idi. Grup 1 a ve $1 b(p=0.021)$, grup $2 a$ ve $2 b(p=0.001)$, grup 1 ve $2(p<0.001)$ arasında ameliyat süresi açısından istatistiksel olarak anlamlı fark vardı. Nüks pterjiyumda her iki teknikte de daha fazla cerrahi süresi gerektirdiği tespit edildi. Her iki grupta hastalarda nüks görülmedi.

Sonuç: Otogreftli pterjiyum cerrahisi, pterjiyumda güvenilir, nüks oranı düşük bir cerrahi yöntemdir. Fibrin doku yapıştırıcı ile yapılan otogreftli pterjiyum cerrahisi daha kısa cerrahi süresine olanak sunması nedeniyle tercih edilebilecek bir yöntem olduğunu düşünmekteyim.

Anahtar Kelimeler: Otogreft, Pterjiyum, Fibrin doku yapıştırıcı, Konjonktiva, Nüks.

\section{Abstract}

Aim: The aim of this study was to compare the fibrin tissue adhesive technique with vicryl suture technique in autograft pterygium surgery.

Patients and Methods: The files of the patients who underwent surgery between June 2016 and August 2019 were retrospectively reviewed. Seventy two patients (Group 1) who underwent autograft pterygium surgery with vicryl suture technique (Primary pterygium Group 1a, recurrent pterygium Group $1 \mathrm{~b}$ ) and 58 patients who underwent autograft pterygium surgery with fibrin tissue adhesive technique (Primary pterygium Group 2a, recurrent pterygium Group $2 \mathrm{~b}$ ) were included.

Results: The mean age of the patients was $47.04 \pm 5.70$ years (ranging between $37-65$ ) in Group 1 and $47.10 \pm 4.88$ years (ranging between $38-57$ ) in Group 2. There was not a statistically significant difference in terms of age between two groups $(p=0.95)$. The mean duration of the surgery was $24.91 \pm 3.08 \mathrm{~min}$, $25.60 \pm 2.20 \mathrm{~min}, 17.62 \pm 2.57 \mathrm{~min}$, and $18.84 \pm 2.83 \mathrm{~min}$ in groups $1 \mathrm{a}, 1 \mathrm{~b}, 2 \mathrm{a}$ and $2 \mathrm{~b}$, respectively. There were statistically significant differences in terms of the duration of the surgery between groups $1 \mathrm{a}$ and $1 \mathrm{~b}$ $(p=0.021)$, groups $2 a$ and $2 b(p=0.001)$, groups 1 and $2(p<0.001)$. Recurrence pterygium was found to require more surgery time in both techniques. Postoperative recurrence was not observed in any of the patients.

Conclusion: Pterygium surgery with conjunctival autograft is a reliable surgical method with low recurrence rates. The duration of surgery in recurrent pterygium was found to be longer in both surgical techniques. It is concluded that autograft pterygium surgery with fibrin tissue adhesive is the preferred surgical method that shortens the duration of the surgery.
\end{abstract}

Key words: Autograft, pterygium, fibrin tissue adhesive, conjunctiva, recurrence
Atıf yapmak için: Turan M. Pterjiyum Cerrahisinde Fibrin Doku Yapıştırıcısı ve Vikril Sütür Tekniği. Selcuk Med J 2020;36(4): 307-311
Açıklama: Yazar bu makalede bahsedilen herhangi bir ürün, aygıt veya ilaç ile ilgili maddi çıkar ilişkisine sahip değildir. Araştırma, herhangi bir dış organizasyon tarafından desteklenmedi.Yazar çalışmanın birincil verilerine tam erişim izni vermek ve derginin talep ettiği takdirde verileri incelemesine izin vermeyi kabul etmektedir. 


\section{GíRiş}

Pterjiyum, bulber konjunktivanın genellikle nazalden korneaya doğru uzanması sonucu oluşan, üçgen şeklinde fibrovasküler dejeneratif bir dokudur $(1,2)$ Etiyolojide birçok etkenin olduğu bilinmektedir. Sıcak, kuru, rüzgarlı iklime ve yüksek UV radyasyonuna maruz kalan coğrafi bölgelerde pterjiyum oluşumu yüksektir (3). Erken evre pterjiyumlar da genellikle semptomatik tedavi (suni gözyaşı preparatları, antialerjik damlalar vs.) ile geçici rahatılık sağlansa da orta ve ileri evre pterjiyumlarda günümüzde tek tedavi seçeneği cerrahidir. Cerrahi tedavide bilinen eski yöntemlerden olan "çıplak sklera tekniği” kullanılmaktadır. Bu teknik ile cerrahi sonrası en sık komplikasyon nüks olup, nüks oranı \%70-90 düzeyinde tespit edilmiştir (4). Yüksek nüks oranı alternatif cerrahi seçenekleri ortaya çıkarmıştır. Günümüzde daha yaygın olarak kullanılan cerrahi yöntem otogreftli pterjiyum cerrahisidir. Bu teknikle birçok alternatif yöntem geliştirilmiştir. Bunlar arasında otogreftin sütürasyonu, yapıştırılması, amnion zarı ile kapatılması, otogreftin yanı sıra yardımcı ilaçların uygulanması yer almaktadır (5-7). Fibrin doku yapıştırıcısı doğal fibrinojen ile trombin reaksiyonunu taklit eden ve birçok cerrahi branşta kullanılan 2 bileşlenli yapıştırıcıdır (8).

Bu çalışmada primer ve nüks pterjiyum tanısıyla otogreftli pterjiyum cerrahisi yapılan hastalarda, konjonktival otogreftin vikril sütür tekniği ve fibrin doku yapıştırıcısı kullanılarak fikse edilmesinin etkinlikleri karşılaştırıldı.

\section{HASTALAR VE YÖNTEM}

Balıkesir Atatürk Şehir Hastanesinde Haziran 2016 - Ağustos 2019 tarihleri arasında primer ve nüks pterjiyum tanısı ile otogreftli pterjiyum cerrahisi uygulanan hastalar çalışmaya alındı. Çalışmaya dahil edilen hastaların dosyaları retrospektif olarak değerlendirildi. Çalışmaya başlamadan önce Balıkesir Üniversitesi Tıp Fakültesi klinik araştırmalar etik kurulundan izin alındı (Karar no 2020/35). Vikril sütür tekniği ile otogreftli pterjiyum cerrahisi uygulanan 72 hasta Grup 1, fibrin doku yapıştırıcısı kullanılarak otogreftli pterjiyum cerrahisi uygulanan 58 hasta Grup 2 olarak ayrıldı. Grup 1'deki hastalar, primer pterjiyumlu 47 hasta Grup 1a ve nüks pterjiyumlu 25 hasta Grup 1 b olarak iki gruba ayrıldı. Grup 2'deki hastalar, primer pterjiyumlu 39 hasta Grup $2 a$ ve nüks pterjiyumlu 19 hasta Grup 2b olarak iki gruba ayrıldı. Grupların cerrahi süresi, komplikasyon oranları değerlendirildi. Tüm cerrahiler tek bir cerrah tarafından yapılmıştır.
Çalışmaya primer ve nüks pterjiyumu olan hastalar dahil edilirken oküler yüzeye alkali yanık hikayesi, kapak malpozisyonu (ektropiyon, entropiyon) olanlar dahil edilmedi.

Cerrahi teknik: Tüm hastalara subkonjonktival enjeksiyon lidokain hidroklorür+Adrenalin (JetokainR (Adeka)) uygulanarak lokal anestezi sağlandı. Pterjiyum dokusu konjonktiva pensi yardımı ile gövde kısmından tutularak kornea yüzeyinden kaldırıldıktan sonra kornea yüzeyinde kalan parçalar kresent bıçak yardımı ile kornea santralinden limbusa doğru eksize edildi. Kornea yüzeyinden ayrılan pterjiyum dokusu sklera üzerindeki kısmı ile beraber konjonktiva makası yardımı ile eksize edildi. Kanama kontrolü sağlandı. Superior kadrandan alınan limbal konjonktival otogreft Grup 1'de vikril sütür kullanılarak Grup 2'de Fibrin doku yapıştırıcı (TISSEELR (EIP Eczacıbası)) kullanılarak skleral yatak üzerine fikse edildi (Şekil 1). Grup 2'de greft ile konjonktiva yara dudakları birbirine temas edecek şekilde forceps yardımı ile yapıştırıldı. Operasyondan sonra hastalara 2 hafta boyunca netilmisin sülfat ve deksametazon disodyum fosfat (NetildexR SIFI S.P.A.) 4x1 damla kullandırıldı. Hastalar 1. gün, 1. hafta, 1. ay, 3. ay ve 6. ayda kontrol edildi (Şekil 1, 2).

Komplikasyonlar intraoperatif ve postoperatif komplikasyonlar olarak ayrıldı. Hemoraji, greftin açılması, korneal lezyon, inflamasyon, greftin

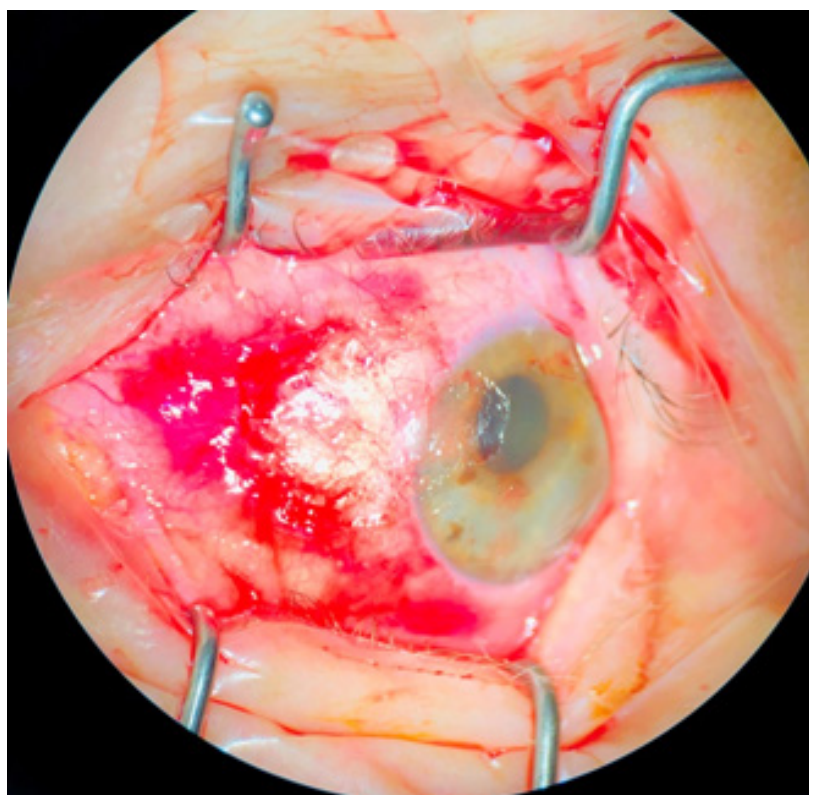

Şekil 1. Fibrin yapıştırıcı uygulanmış hastanın intraoperatif görünümü. 


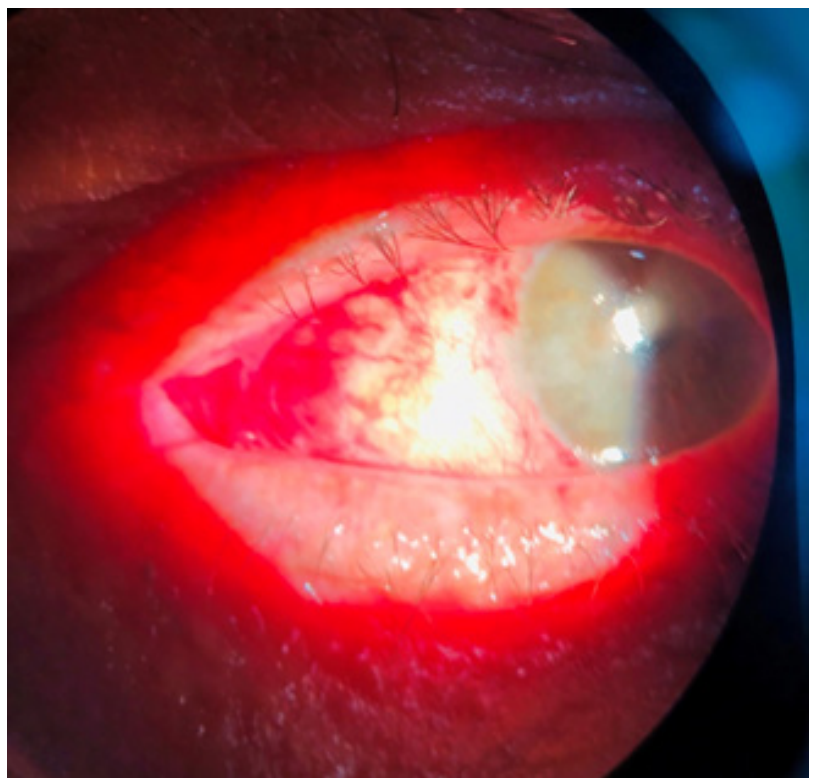

Şekil 2. Fibrin yapıştırıcı uygulanmış hastanın postoperatif 1. hafta görünümü.

retraksiyonu ve nüks açısından değerlendirildi. Nüks pterjiyum, limbusu $1 \mathrm{~mm}$ aşan fibrovasküler doku olarak tanımlandı.

İstatistiksel Analizde, SPSS analiz programı 20.0 versiyonu kullanıldı. Gruplar arasında ki karşılaştırma için bağımsız örneklem t testi kullanılarak yapıldı. P değeri $<0.05$ anlamlı kabul edildi.

\section{BULGULAR}

Hastaların yaşları değerlendirildiğinde Grup 1a ortalama 47,30 $\pm 4,78,(37-56)$ yıl iken Grup 1 b ortalama $46,56 \pm 7,2$, (37-65) yıl idi. Grup 2a'da ortalama $48,49 \pm 4,83$, (38-57) yıl iken Grup 2b'de ortalama

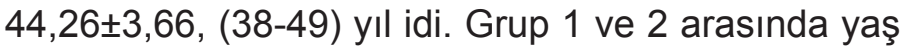
açısından anlamlı fark görülmedi $(p=0.95)$. Grup 1'de ortalama cerrahi işlem süresi $25,15 \pm 2,81$, (18-35) dakika (dk) iken grup 2'de 17,98 $\pm 2,68$, (14-23) dk. idi. Grup 1 ve Grup 2' deki hastaların cerrahi işlem süreleri değerlendirildiğinde gruplar arasında istatistiksel olarak anlamlı fark olduğu görüldü ( $p<0,001)$, (Tablo 1). Hem Grup1a ve Grup 1b, hemde Grup 2a ve 2b'de cerrahi işlem süresi nüks pterjiyumda anlamlı olarak daha uzun idi ( $p=0,021,<0,001$, sırasıyla). Hastaların takip süreleri (ay) değerlendirildiğinde en kısa takip süresi 6 ay, en uzun takip süresi 37 ay idi (Tablo 2). Grup 1'de ortalama takip süresi $25,69 \pm 8,03$ ay iken, Grup 2'de 12,24 $\pm 3,78$ ay idi.

İntraoperatif hemoraji, hiçbir olguda koter kullanmamızı gerektirecek kadar olmadı. Ancak postoperatif 1 . hafta kontrollerinde $2(\% 2,8)$ hastanın Grup 1'de, $2(\% 3,4)$ hastanın Grup 2'de greft altına kanamasının olduğu görüldü. Bu komplikasyon iki grup arasında istatistiksel olarak anlamlı değildi $(p=0,82)$. 1. ay kontrollerinde hemorajinin kaybolduğu görüldü. Greftin açılması komplikasyonu değerlendirildiğinde

Tablo 1. Grupların minimum ve maksimum cerrahi işlem süreleri ve ortalama işlem süresi.

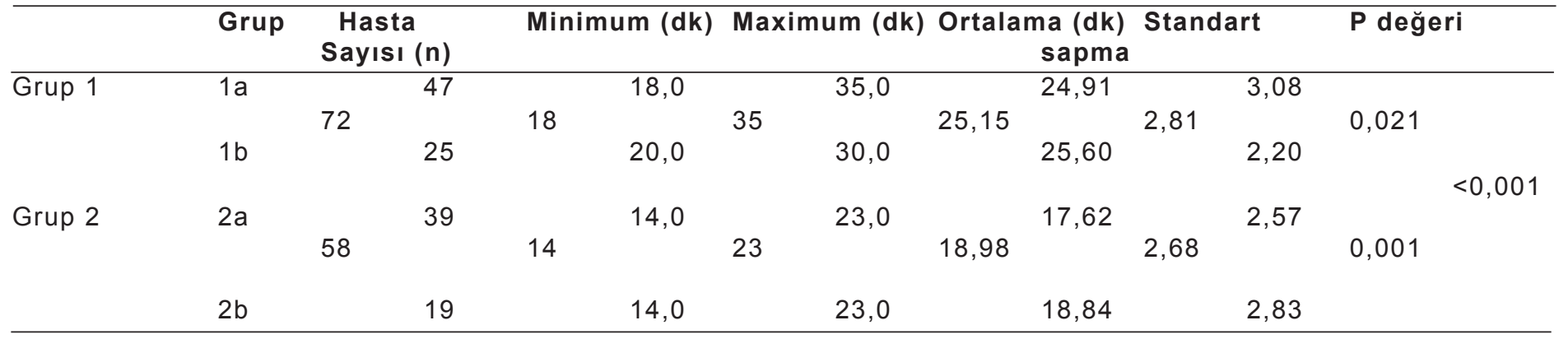

Tablo 2. Grupların minimum ve maksimum takip süreleri ve ortalama takip süresi.

\begin{tabular}{|c|c|c|c|c|c|c|}
\hline & Grup & $\begin{array}{c}\text { Hasta } \\
\text { Sayısı (n) }\end{array}$ & Minimum (ay) & Maximum (ay) & Ortalama (ay) & Standart sapma \\
\hline \multirow[t]{3}{*}{ Grup 1} & $1 \mathrm{a}$ & 47 & 8,0 & 37,0 & 28,91 & 7,12 \\
\hline & & 72 & 8,0 & 37 & 25,69 & 8,03 \\
\hline & $1 \mathrm{~b}$ & 25 & 9,0 & 29,0 & 19,64 & 5,94 \\
\hline \multirow[t]{3}{*}{ Grup 2} & $2 a$ & 39 & 6,0 & 19,0 & 12,49 & 4,15 \\
\hline & & 58 & 6,0 & 19 & 12,41 & 3,71 \\
\hline & $2 b$ & 19 & 6,0 & 17,0 & 11,74 & 3,41 \\
\hline
\end{tabular}




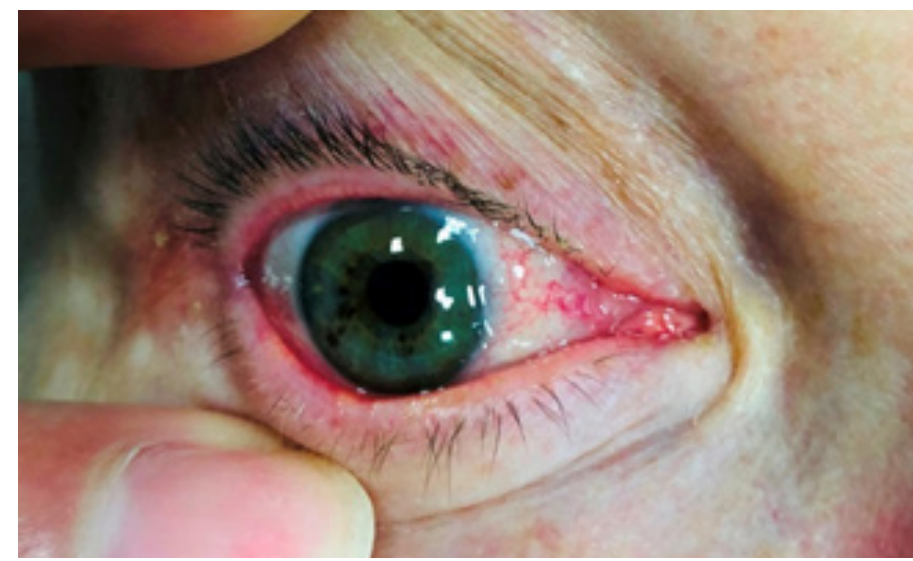

Şekil 3. Fibrin yapıştırıcı uygulanmış hastanın 1. Ay görünümü.

Grup 1'de $3(\% 4,2)$ hastanın sütürlerinde açılma olduğu, Grup 2'de 1 (\%1,7) hastanın greftinde kayma olduğu görüldü. Ancak bu fark istatistiksel olarak anlamlı değildi $(p=0,21)$. Greftinde kayma olan hasta tekrar fibrin doku yapıştırıcı ile yapıştırıldı. Korneal dokunun tüm hastalarda 1 . hafta kontrolünde epitelize olduğu görüldü. İnflamasyon açısından değerlendirildiğinde Grup 1'de $2(\% 2,8)$ hastada konjonktival otogreftin inflame olduğu ancak 1. ay kontrolünde iyileşmiş olduğu görüldü. Çalışmamıza dahil edilen hastalarda hem Grup 1 hem de Grup 2'de takip süresi boyunca nüks görülmedi.

\section{TARTIŞMA}

Pterjiyum cerrahisinde ilk cerrahi yöntem olan çıplak sklera tekniğinin nüks oranının yüksek olması nedeniyle alternatif cerrahi yöntemler düşünülmüştür. Pterjiyum cerrahisinde konjonktival otogreft yöntemi ilk defa 1985 yılında Kenyon et al. (9) tarafından tanımlanmıştır. Cohen et al. (10) tarafından 1993 yılında pterjiyum cerrahisinde fibrin doku yapıştırıcı kullanımını tanımlamıştır. Çalışmamızda hem primer pterjiyumda hemde nüks pterjiyumda, vikril sütür ve fibrin doku yapıştırıcı kullanılarak otogreftli pterjiyum cerrahisi yapılan hastalar karşılaştırıldı. Otogreftin yerleştirilmesi sütürle yapıldığı zaman cerrahi süresinde uzama, hasta uyumsuzluğu, sütüre bağı şikayetler ortaya çıkabilmektedir (11). Bahar et al. (12) konjonktival otogreft pterjiyum cerrahisinde fibrin doku yapıştırıcı ve sütür kullanarak yaptıkları çalışmalarında, fibrin doku yapıştırıcı kullandıkları grupta cerrahi süresinin daha kısa ve ameliyat sonrası rahatsızlık hissinin daha az olduğunu tespit etmişlerdir.
Çalışmamızda cerrahi süresi değerlendirildiğinde, en uzun süre vikril sütür tekniği ile nüks pterjiyum ameliyatı yapılan grupta olduğu görüldü. En kısa cerrahi süresinin fibrin doku yapıştırıcı ile yapılan primer pterjiyumlu grupta olduğu görüldü.

Özdamar et al. (13) yaptıkları çalışmasında fibrin doku yapıştırıcı tekniği ile pterjiyum cerrahisi uygulanan grupta hasta konforunun daha iyi olduğunu bulmuş ve takip süresi boyunca her iki grupta da nüks gözlenmediğini bildirmişlerdir. Literatürde yapılan diğer çalışmalar değerlendirildiğinde, Dadeya et al. (14) transpozisyonel flep tekniği ile yaptıkları pterjiyum cerrahisinde, cerrahi sürenin otogreft yönteminden daha kısa olduğunu gözlemleyerek rotasyonel flep için \% 5.58 ve otogreft için \%5.55 nüks oranları ile önemli miktarda cerrahi zaman tasarrufu sağladığını bildirmişlerdir. Bununla birlikte, Wu et al. (15) transpozisyonel flep tekniğinden sonra nüks oranını \% 35 olarak bildirmişlerdir. Ma et al. (16) retrospektif olarak yaptıkları çalışmada, primer pterjiyum eksizyonundan sonra amniyotik membranın etkinliğini ve güvenilirliğini, konjonktival otogreft ve topikal\% 0.02 mitomisin C ile karşılaştırdıklarında, gruplar arasında rekürrens oranlarında anlamlı bir fark olmadığını bildirmişlerdir. Çalışmamızda hem vikril sütür tekniği hemde fibrin doku yapıştırıcı tekniği uygulanan grupta takip süresi içinde nüks görülmedi.

Otogreftli pterjiyum cerrahisinde vikril sütür yöntemi kulanılıyor ise yerleştirilen greftin gergin olmamasına dikkat edilmesi gerekmektedir. Dolayısıyla alınan greftin skleral alanı yeterince kapatacak büyüklükte olması gerekir. Aksi takdirde sütürlerde açılma meydana gelebilir. Çalışmamızda 3 hastanın gergin grefte bağlı sütürlerinde açılma olduğu görüldü. Benzer şekilde fibrin yapıştırıcı kullanılan hastalarda da otogreftin yeterince büyük olması postoperatif gereftin kayması ve açılmasını engelleyecektir. Greft kaymasını önlemek için postoperatif 48 saat sıkı bandaj uygulaması faydalı olabilir (17). Ayrıca hastalar gözünü hem oluşan rahatsızlıktan dolayı ovalamaktan, hemde travmadan koruması hususunda özellikle uyarılmalıdır. Çalışmamızda 1 hastanın 1. hafta kontrolünde, greftinde kayma olduğu gözlendi. Hastanın grefti tekrar yapıştırıldı.

\section{SONUÇ}

Otogreftli pterjiyum cerrahisi, pterjiyumda güvenilir, nüks oranı düşük bir cerrahi yöntemdir. Fibrin doku yapıştırıcı ile yapılan otogreftli pterjiyum cerrahisi daha kısa cerrahi süresine olanak sunması nedeniyle tercih edilebilecek bir yöntemdir. 
Çıkar Çatışması: Çalışmada herhangi bir çıkar çatışması yoktur.

Finansal Çıkar Çatışması: Çalışmada herhangi bir finansal çıkar çatışması yoktur.

Yazışma Adresi: Meydan Turan, Balıkesir Atatürk Şehir Hastanesi, Göz Kliniğii, Balıkesir, Türkiye

e-mail: meydanturan@gmail.com

\section{KAYNAKLAR}

1. Grimmet MR, Holland EJ. Management of pterygium. In: Krachmer JH, Mannis MJ, Holland EJ, eds. Cornea, surgery of cornea and conjunctiva. Vol III, Mosby: St. Louis, Philadelphia, 1997:1873-5.

2. Hillgers JHC. Pterygium: Its incidence, heredity and etiology. Am J Ophthalmol 1960;50:635-44.

3. Cárdenas-Cantú E, Zavala J, Valenzuela J, et al. Molecular basis of pterygium development. Semin Ophthalmol 2016;31:567-83.

4. Starck T, Kenyon KR, Serrano F. The management of ptergium. Cornea 1991;10:611-23.

5. Elmas K, Katırcıoğlu Y, Aslan BS, et al. Primer pterjiyum rezeksiyonunda amniyon grefti, konjonktival otogreft ve primer kapama tekniklerinin karşılaştırılması. Turk J Ophthalmol 2002;32:337-42.

6. Tananuvat N, Martin T. The results of amniotic membrane transplantation for primary pterygium compared with conjunctival autograft. Cornea 2004;23:458-63.

7. Katırcıoğlu YA, Altıparmak UE, Duman S. Comparison of three methods for the treatment of pterygium: Amniotic membrane graft, conjunctival autograft and conjunctival autograft plus mitomycin C. Orbit 2007;26:5-13.

8. Schlag G, Aschler PW, Steinkogler FJ, et al. Fibrin sealing in surgical and nonsurgical fields, Vol 5. Neurosurgery, ophthalmic surgery, ENT. Berlin: Springer Verlag 1994:97106.
9. Kenyon KR, Wagoner MD, Hettinger ME. Conjunctival autograft transplantation for advanced and recurrent pterygium. Ophthalmology 1985;92:1461-70.

10. Cohen RA, McDonald MB. Fixation of conjunctival autografts with an organic tissue adhesive [letter]. Arch Ophthalmol 1993;111:1167-8.

11. Esen D, Ozkan MH, Buttanrı BI, et al. Pterjiyum cerrahisinde fibrin yapıştırıcısı ile konjonktivalimbal otogreft uygulaması. TJO 2010;40:266-70.

12. Bahar I, Weinberg D, Dan G, et al. Pterygium surgery: Fibrin glue versus vicryl sutures for attaching closure. Cornea 2006;25:1168-72.

13. Ozdamar Y, Mutevelli S, Han U, et al. A comparative study of tissue glue and vicryl suture for closing limbal-conjunctival autografts and histologic evaluation after pterygium excision. Cornea 2008;27:552-8.

14. Dadeya S, Malik KP, Gulliani BP. Pterygium surgery: Conjunctival rotation autograft versus conjunctival autograft. Ophthalmic Surg Lasers 2002;33:269-74.

15. Wu WK, Wong VW, Chi SC, et al. Surgical management of double-head pterygium by using a novel technique: Conjunctival rotational autograft combined with conjunctival autograft. Cornea 2007;26:1056-9.

16. Ma DH, See LC, Liau SB, et al. Amniotic membrane graft for primary pterygium: Comparison with conjunctival autograft and topical mitomycin $\mathrm{C}$ treatment. $\mathrm{Br} \mathrm{J}$ Ophthalmol 2000;84(9):973-8.

17. Gong J, Fan J, Shen T, et al. Comparison of self-made cryopreservative fibrin glue and commercial fibrin glue kit in pterygium surgery: 1-year follow-up. Acta Ophthalmol 2018;96:e152-e155. 